\title{
Prof. Dr. habil. Klaus Löhle 75 Jahre
}

Am 30. Januar 2004 vollendet Univ. Prof. em. Dr. KLAUS LÖHLE sein 75. Lebensjahr. Wir nutzen diese Gelegenheit unserem Freund und hochverehrten Kollegen zu seinem Jubiläumstag sehr herzlich zu gratulieren. Dies stellvertretend für viele Kollegen aus der Wissenschaft und Zuchtpraxis, ehemalige Mitarbeiter und Schüler. Sein Lebenswerk wurde in dieser Zeitschrift und an anderer Stelle bereits umfangreich gewürdigt, so dass hier Biographisches nur fragmentarisch erwähnt wird.

KLAUS LÖHLE wurde am 30. Januar 1929 in Saalfeld geboren. Sein Elternhaus prägte schon in der Kindheit Eigenschaften wie Fleiß, Pflichtbewusstsein, seine humanistische Lebensauffassung, wissenschaftliche Neugier aber auch seine Liebe zum Tier. Als er im Alter von zehn Jahren mit der Haltung von Kaninchen begann, wusste er nicht, dass dieses Tier neben anderen Tierarten einmal seinen beruflichen Lebensweg begleiten sollte. Sein Werdegang ist durch Zielstrebigkeit und Kontinuität gekennzeichnet. Nach Abitur am Realgymnasium in Saalfeld, landwirtschaftlicher Lehre, Studium an der Friedrich-Schiller-Universität Jena, kam er an das dortige Institut für Tierzucht und Milchwirtschaft. Er wurde Assistent und promovierte 1954 mit einer Arbeit über Kaninchen bei FRITZ HOFMANN. Als Oberassistent und später Dozent für Kleintierzucht, übernahm er die Abteilung Kleintierzucht am gleichen Institut sowie die wissenschaftliche Leitung des Universitätsgutes Altenberga. Hier konnte er neben der Rinder- und Schweinezucht einen umfangreichen Experimentierbestand für Ziegen, Kaninchen und Geflügel aufbauen und nutzen. Pionierarbeit leistete er bei der Entwicklung der künstlichen Besamung insbesondere der Ziegen, Kaninchen und des Geflügels sowie beim Aufbau der Hühnerleistungsprüfung in der DDR. Seit seiner Jenaer Zeit bis zur Emeritierung suchte er die enge Zusammenarbeit mit Züchtern und Zuchtorganisationen, wohl wissend dass dieses wechselseitige „Geben und Nehmen“ für eine praxisrelevante Lehre und Forschung unerlässlich ist. Im Jahr 1966 habilitierte er sich an der Landwirtschaftlichen Fakultät in Jena mit einem Thema zur Fleischqualität verschiedener Hühnerrassen und deren Kreuzungen.

Zum ordentlichen Professor berufen, erhielt er im gleichen Jahr als Nachfolger von FRITZ LÜTZENBERG einen Ruf als Direktor des Institutes für Geflügel- und Pelztierzucht der Humboldt-Universität zu Berlin mit den Versuchsstationen Blumberg (Geflügel und Kaninchen) und Strausberg (Pelztiere). Es folgten 28 Jahre eines erfolgreichen Wirkens in Lehre und Forschung an der Humboldt-Universität, dieser ehrwürdigen und traditionsreichen Bildungsstätte. Zahlreich und vielfältig sind die Arbeitsfelder seiner wissenschaftlichen Tätigkeit 
auf deren Darstellung hier verzichtet wird. Eingedenk des Mottos seiner Jenaer Schule, dass Wissenschaft nur dann erfolgreich angewendet werden kann, wenn sie verständlich mitgeteilt wird, kennen wir die Ergebnisse seiner Arbeit aus der großen Anzahl wissenschaftlicher und populärwissenschaftlicher Veröffentlichungen in Zeitschriften, Büchern, Buchbeiträgen oder Filmen, die sein äußerst kreatives Schaffen aus fünf Jahrzehnten nachhaltig belegen. Erwähnt sei nur das unter seiner Mitherausgeberschaft in 2. Auflage vorliegende Handbuch „Künstliche Besamung beim Nutztier“ des Fischer-Verlages, welches gegenwärtig auch international das umfassendste Nachschlagewerk auf diesem Gebiet darstellt. Genannt sei auch das unlängst im Ulmerverlag herausgebrachte Buch „Ziegen und Schafe“. Im Zusammenhang mit seiner Öffentlichkeitsarbeit ist die inzwischen 32jährige bis in die Gegenwart fortgesetzte aktive Tätigkeit im Redaktionskollegium unserer Zeitschrift hervorzuheben. Nicht zuletzt hat durch seine Mitwirkung das „Archiv für Tierzucht“ ihr heutiges internationales Niveau erreicht, wofür ihm mein ganz besonderer Dank gilt.

Als Hochschullehrer wirkte KLAUS LÖHLE außerordentlich erfolgreich und widmete sich der soliden Bildung seiner Studenten mit großer Hingabe. Er verstand es sein umfangreiches fachliches Wissen und Können verbunden mit einem wohldosierten Maß an Allgemeinbildung in bewundernswerter Art und Weise zu vermitteln. Seine brillante Rhetorik und sein intellektueller und anspruchsvoller Humor, machten die Vorlesungen für seine Studenten stets zu einem echten Erlebnis. Das galt übrigens auch für seine Vorträge, die zu den Höhepunkten auf Geflügel- und Kleintierzuchttagungen zählten und auf denen er immer ein gern gesehener Gast war. Als Hochschullehrer legte er aber auch Wert darauf den Studenten akademische Traditionen und Bildung zu vermitteln. Aus diesem Selbstverständnis heraus war er Studenten und Schülern stets Lehrer und Vorbild zugleich. Das gilt in besonderem Maße für die Förderung des wissenschaftlichen Nachwuchses, dem sein ganzes Augenmerk galt. Unter seiner Betreuung wurden zahlreiche junge Agrarwissenschaftler zur Promotion oder Habilitation geführt, die ihm bis heute freundschaftlich verbunden sind und zu den Gratulanten des Jubilars zählen.

Neben Lehre und Forschung widmete sich KLAUS LÖHLE auch der Arbeit in zentralen Gremien der Universität bis zu seinen bleibenden Verdiensten in der Phase der Fusion und Neugründung der Landwirtschaftlich-Gärtnerischen Fakultät an der Humboldt-Universität zu Berlin.

Viele, die den Lebensweg von KLAUS LÖHLE kreuzten, erinnern sich immer sehr gern an Begegnungen mit ihm. Damit verbinden sich fachliche Kompetenz, sein immer gern gegebener Rat oder helfende Kritik, seine Toleranz, sein feinsinniger Humor, das unerschöpfliche Reservoire geistvoller Anekdoten oder die Liebe zu herzlicher Geselligkeit. Der Laudator wünscht sich auch im Namen aller Gratulanten in den kommenden Jahren noch viele freundschaftliche Begegnungen, auch mal bei einem Glas Rotwein. Für die Zukunft wünschen wir KLAUS LÖHLE alles erdenklich Gute, Gesundheit, Zeit für seine philologischen Studien, zum Musizieren und der Erfüllung anderer eigener Wünsche, vor allem aber viele schöne, gemeinsame Jahre mit seiner Gattin, den Kindern und Enkeln, denen seine ganze Liebe gilt. Lieber KLAUS LÖHLE, im Namen aller Gratulanten „Glückwunsch“, schön das es Dich gibt, bleib so wie Du bist. 